\title{
A novel Mtd splice isoform is responsible for trophoblast cell death in pre-eclampsia
}

\author{
N Soleymanlou ${ }^{1,2,3}, \mathrm{Y} \mathrm{Wu}{ }^{1}$, JX Wang ${ }^{2}, \mathrm{~T}$ Todros ${ }^{4}$, F letta ${ }^{1}$, \\ A Jurisicova ${ }^{1,3,5}$, M Post $^{2,3,6}$ and I Caniggia ${ }^{\star, 1,3,5,6}$ \\ ${ }^{1}$ Mount Sinai Hospital, Toronto, Ontario, Canada M5G 1X5 \\ 2 The Hospital for Sick Children, Toronto, Ontario, Canada M5G 1X8 \\ ${ }^{3}$ Department of Physiology, Faculty of Medicine, University of Toronto, Toronto, \\ Ontario, Canada \\ ${ }^{4}$ Department of Obstetrics and Gynecology, Maternal-Fetal Medicine Unit, \\ University of Turin, Italy \\ 5 Department of Obstetrics and Gynecology, Faculty of Medicine, University of \\ Toronto, Toronto, Ontario, Canada \\ ${ }^{6}$ Department of Pediatrics, Faculty of Medicine, University of Toronto, Toronto, \\ Ontario, Canada \\ * Corresponding author: I Caniggia, Mount Sinai Hospital, Samuel Lunenfeld \\ Research Institute, 600 University Avenue, Room 871C, Toronto, Ontario, \\ Canada M5G 1X5. Tel: + 1416586 4803; Fax: + 1416586 8588; \\ E-mail: caniggia@mshri.on.ca
}

Received 29.7.04; revised 29.11.04; accepted 28.12.04; published online 18.3.05 Edited by M Piacentini

\begin{abstract}
Pre-eclampsia is a serious disorder of human pregnancy, characterized by decreased utero-placental perfusion and increased trophoblast cell death. Presently, the mechanisms regulating trophoblast cell death in pre-eclampsia are not fully elucidated. Herein, we have identified a novel Mtd/Bok splice isoform (Mtd-P) resulting from exon-II skipping. Mtd-P expression was unique to early-onset severe pre-eclamptic placentae as assessed by quantitative real-time-PCR and immunoblotting. Mtd-P overexpression in cell lines (BeWo: cytotrophoblast-derived; and $\mathrm{CHO}$ : ovary-derived) resulted in increased apoptotic cell death as assessed by caspase-3 cleavage, internucleosomal DNA laddering and mitochondrial depolarization. Moreover, Mtd-P expression increased under conditions of low oxygenation/oxidative stress in human villous explants. Antisense knockdown of Mtd under conditions of oxidative stress resulted in decreased caspase-3 cleavage. We conclude that under conditions of reduced oxygenation/ oxidative stress, Mtd-P causes trophoblast cell death in preeclampsia and hence may contribute to the molecular events leading to the clinical manifestations of this disease.

Cell Death and Differentiation (2005) 12, 441-452.

doi:10.1038/sj.cdd.4401593

Published online 18 March 2005
\end{abstract}

Keywords: apoptosis; Matador (Mtd); placenta; pre-eclampsia; trophoblast; oxidative stress

Abbreviations: AS, antisense; $\mathrm{CHO}$, Chinese hamster ovary; $\mathrm{CT}$, cytotrophoblast; EVT, extravillous trophoblast; IUGR, intrauterine growth restriction; JC-1, 5,5',6,6'-tetrachloro-1,1',3,3'tetraethylbenzimidazol-carbocyanine iodide; Mtd/Bok, Matador/
Bcl-2-related ovarian killer; qRT-PCR, quantitative real-time PCR; S, sense; SK, syncytial knots; ST, syncytium/syncytiotrophoblast; STBM, syncytiotrophoblast microfragment

\section{Introduction}

Pre-eclampsia, a complex and serious disorder of human pregnancy, is presently a leading cause of fetal and maternal morbidity and mortality worldwide, affecting approximately $5-7 \%$ of all pregnancies. ${ }^{1}$ Clinical diagnosis and symptoms are based on sudden onset of hypertension accompanied by proteinuria and edema. Although, the etiology of this disease remains unclear, it is accepted that the placenta plays a central role in its pathogenesis.

A key histopathologic feature of pre-eclampsia is the shallow trophoblast invasion of the maternal site. Doppler studies have demonstrated that the pre-eclamptic fetomaternal interface experiences an abnormally elevated myometrial vascular resistance and decreased utero-placental perfusion as a result of incomplete trophoblast-mediated remodeling of myometrial spiral arteries, which retain their vasoactive characteristic. ${ }^{2,3}$ In this condition, inadequate placental perfusion leads to oxidative stress, placental hypoxia/ischemia and, in severe cases, infarctions. ${ }^{4-6}$

It is postulated that in pre-eclampsia, excessive placental shedding of syncytiotrophoblast microfragments (STBMs) in the maternal circulation, due to elevated apoptosis, may directly contribute to the initiation of a Th1-type maternal inflammatory response culminating in systemic endothelial cell damage. ${ }^{4,7}$ The renewal of placental syncytium, known to be mediated via apoptosis, is a physiological process observed throughout pregnancy, and is believed to be initiated in the underlying mononucleated progenitor cytotrophoblast (CT) layer. ${ }^{8}$ Importantly, trophoblast apoptosis as well as syncytial shedding has been shown to be significantly increased in pre-eclampsia. ${ }^{9,10}$ The exact mechanisms causing these events remain unclear.

Proteins within the Bcl-2 family are important intrinsic regulators of apoptosis in normal development and disease. ${ }^{11,12}$ Placental expression of antiapoptotic molecules $\mathrm{Bcl}-2$ and $\mathrm{Mcl}-1$ has been reported in the syncytium (ST) as well as in CT cells of placentae from normal pregnancies. ${ }^{8,13}$ While some studies have reported that $\mathrm{Bcl}-2$ expression is unchanged in placentae of pregnancies complicated by pre-eclampsia, ${ }^{14,15}$ others have reported a decreased expression of this molecule in severe pre-eclampsia when compared to controls. ${ }^{16}$ Both proapoptotic molecules Bax and Bak are expressed in villous CT cells and in syncytium of normal placentae ${ }^{13}$ but their expression is not different between placentae of pre-eclamptic and control subjects. ${ }^{14,15}$ Mtd/Bok (Mtd: Matador/Bok: Bcl-2-related ovarian killer) belongs to the multi-domain pore-forming subfamily of proapoptotic Bcl-2 family members including Bax and Bak. ${ }^{17,18}$ Mtd expression is greatest in reproductive tissues, ${ }^{17}$ 
but its human placental expression is unknown. To date, two Mtd splice isoforms have been characterized: Mtd-L, a fulllength proapoptotic protein that primarily interacts with $\mathrm{Mcl}-1$, and Mtd-S, a shorter proapoptotic transcript resulting from fusion of $\mathrm{BH} 3$ and $\mathrm{BH} 1$ domains. The function of this short isoform cannot be antagonized by any known antiapoptotic Bcl-2 family member. ${ }^{19}$ Herein, we have investigated Mtd expression in the human placenta. We report the identification and functional characterization of a novel splice variant of the Mtd gene (Mtd-P) and its expression and significance in normal placental development as well as in placental tissue from pregnancies complicated by pre-eclampsia.

\section{Results}

\section{Mtd gene expression in first-trimester placental tissues}

The expression of previously characterized transcripts of Mtd (Mtd-L and Mtd-S) was observed in first-trimester tissues (6-12 weeks) (Figure 1a). While Mtd-L expression (794 bp) was constant throughout first-trimester samples, Mtd-S expression (665 bp) appeared to decrease in tissues from 10 to 12 weeks when compared to earlier gestations. Importantly, a 546 bp band exhibiting strong Mtd-specific hybridization was observed predominantly around 6-8 weeks. Sequencing of the 546 bp band revealed a novel Mtd transcript referred to in this study as Mtd-P.

\section{Mtd-P is a novel Mtd transcript resulting from exon II skipping}

Sequence analysis of Mtd-P transcript showed a $249 \mathrm{bp}$ deletion spanning bp 217-466 in the full-length mRNA (NM_032515). This deletion included part of the $5^{\prime}$ UTR, the original start methionine, the $\mathrm{BH} 4$ and part of the $\mathrm{BH} 3$ domain, resulting in a deletion of 83 amino acids (Figure 2a). The genomic structure of Mtd is composed of five putative exons and four introns localized on chromosome $2 q 37.3$. Mtd-P was noted to undergo exon II skipping (orange box), resulting in deletion of $\mathrm{BH} 4$ and part of $\mathrm{BH} 3$ domains. The protein product of Mtd-P has a theoretical molecular weight of approximately $15 \mathrm{kDa}$ (Figure 2b). The putative pore-forming region encoded by exon IV is retained in all isoforms.

\section{Mtd protein expression in first-trimester placental tissues}

Next, we examined Mtd protein expression using an antibody generated against a peptide sequence derived between $\mathrm{BH} 2$ and $\mathrm{BH} 1$ domains of $\mathrm{Mtd}-\mathrm{L}$, thus recognizing all known isoforms. Immunoblotting confirmed expression of previously characterized Mtd isoforms (Mtd-L and Mtd-S) in firsttrimester tissues in addition to a novel Mtd-specific band with an apparent molecular weight of $15 \mathrm{kDa}$, corresponding to the predicted molecular weight of Mtd-P (Figure 1b). Mtd-S runs at its predicted molecular weight $(18 \mathrm{kDa})$, while Mtd-L (predicted molecular weight: $23 \mathrm{kDa}$ ) was observed at an apparent molecular weight of $28 \mathrm{kDa}$, possibly due to posttranslational modifications (Figure 1b). While Mtd-L and Mtd-S protein expression was constant across first trimester gestations based on Western blotting and densitometric analyses, Mtd-P was the only isoform whose expression significantly increased around 6-8 weeks when compared to later gestations (2.2-fold increase, $P=0.04$ ) (Figure 1d). Similar to protein expression, quantitative real-time PCR (qRT-PCR) demonstrated that while Mtd-P transcript expression increased significantly in early first-trimester compared to later gestations (3.4-fold increase, $P=0.03$ ), Mtd-L gene expression was unchanged across first trimester samples (Figure 1c).

Next, Mtd spatial localization was assessed by immunohistochemistry. Positive immunoreactivity was mostly observed in early first-trimester sections (6 weeks) and was predominately localized to the progenitor mononucleated CT cells (Figure 1e, left panel). Low/absent Mtd immunoreactivity was noted in the multinucleated syncytiotrophoblast layer (ST). In contrast, tissue sections from later first-trimester gestations (12 weeks) exhibited low/absent Mtd expression in CT cells (right panel), while Mtd-positive immunoreactivity was detected in the apical membrane of the syncytiotrophoblast layer. Stromal regions were Mtd negative. Neighboring control sections (no $1^{\circ} \mathrm{Ab}$ ) were also Mtd negative. Finally, Mtd expression colocalized with terminal deoxynucleotidyl transferase dUTP nick end labeling (TUNEL) staining also predominantly observed in early first trimester compared to later gestations (lower panels).

\section{Mtd expression is elevated in pre-eclampsia}

As pre-eclampsia is characterized by increased trophoblast cell death, we next examined whether Mtd expression was altered in placentae complicated by this disease. Mtd gene expression was increased in pre-eclamptic placental tissues particularly with respect to Mtd-P when compared to normotensive age-matched controls (Figure 3a). Densitometric analyses (RT-PCR followed by Southern blot) revealed that elevated gene expression was only significant with respect to Mtd-L and Mtd-P transcripts in pre-eclamptic samples, but not Mtd-S (Mtd-L: 2.7-fold, $P=0.004$; Mtd-S: 1.7-fold (not significant); Mtd-P: 3.5 -fold, $P=0.006$ ). qRTPCR analyses further validated that the expression of Mtd-L and particularly that of Mtd-P increased in pre-eclamptic tissues when compared to preterm age-matched normotensive control patients (Mtd-L: 2.1-fold, $P=0.03$; Mtd-P: 3.3fold, $P=0.01$; Figure $3 \mathrm{c}$ ). Increased Mtd protein content in early-onset pre-eclampsia was particularly notable with respect to Mtd-P (Figure $3 \mathrm{~b}$ ). Protein densitometric analysis revealed that Mtd- $L$ and $M t d-P$ were significantly elevated in pre-eclamptic tissues by approximately 3.6-fold $(P<0.05)$ and 5.1-fold $(P<0.05)$ respectively, when compared to preterm age-matched control tissues (Figure $3 d$ ). Similar to Mtd-S gene expression, the 1.9-fold increase in Mtd-S protein level in pre-eclampsia was not statistically significant when compared to controls (Figure 3d).

We next compared Mtd protein expression between preeclamptic pregnancies (early and late onset) and normotensive pregnancies affected by intrauterine growth restriction (IUGR), essential hypertension as well as normal term deliveries. We observed that only pre-eclamptic placentae 
a
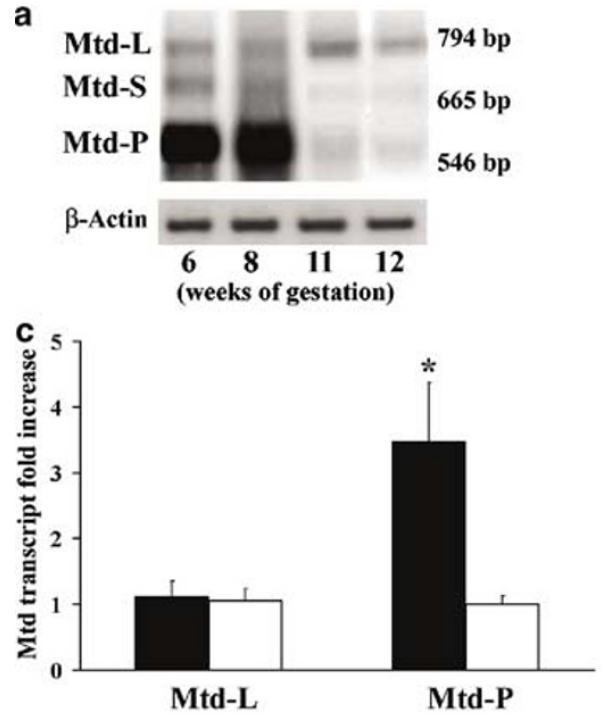

e
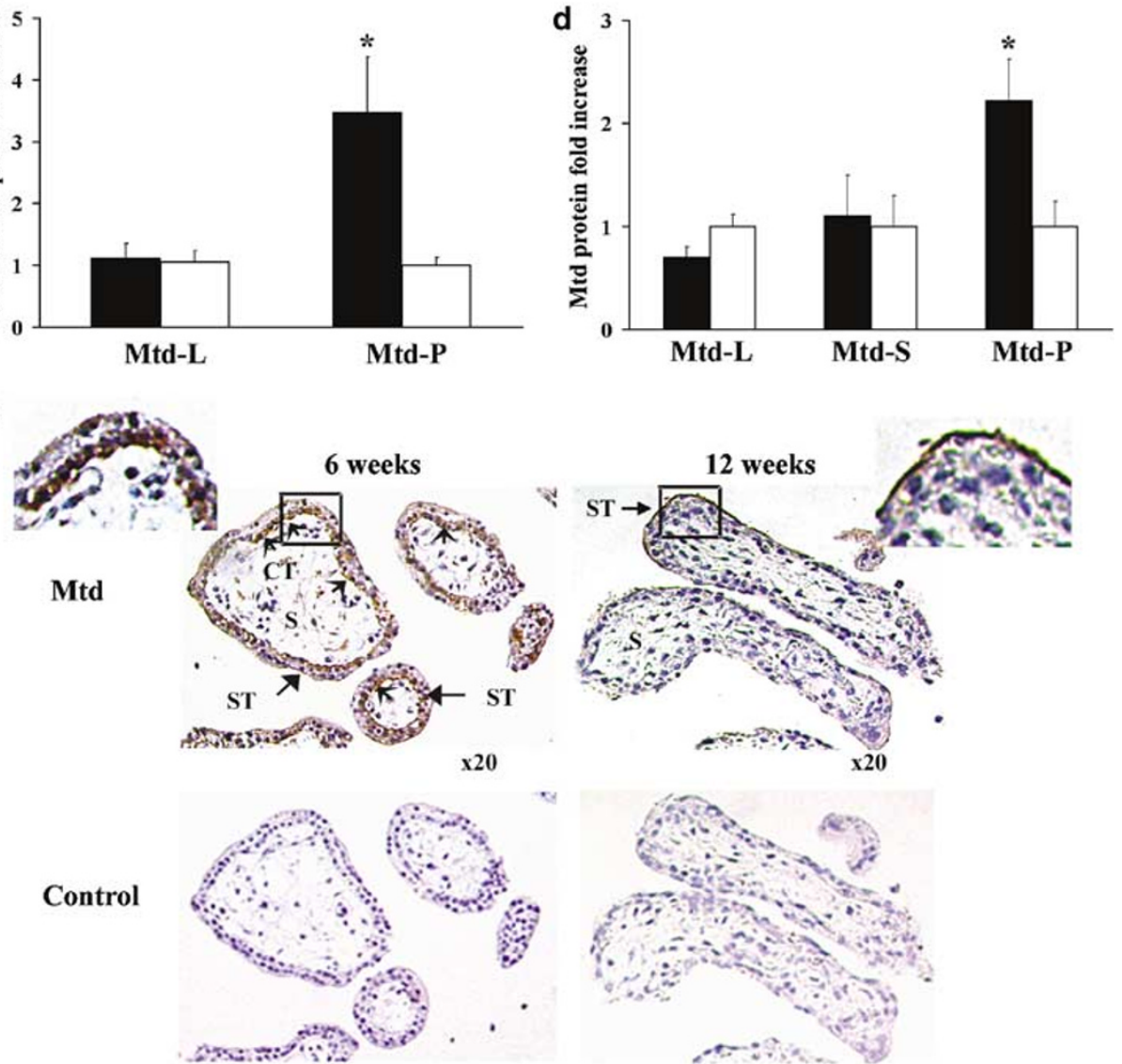

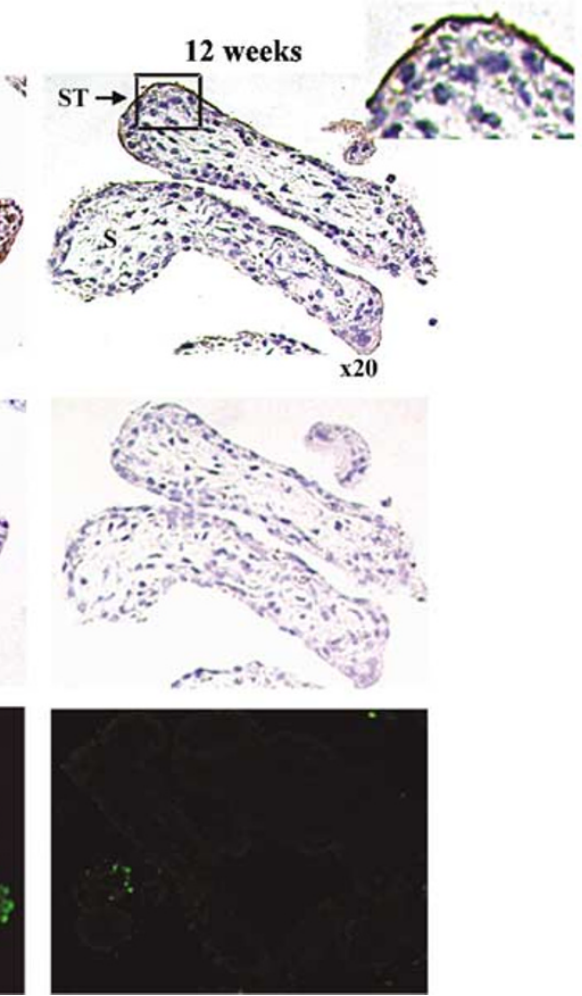

Figure 1 Mtd expression in first-trimester placental tissues. (a) RT-PCR followed by Southern hybridization to a ${ }^{32}$ P-labeled full-length Mtd cDNA in trimester placental tissues. $\beta$-Actin is shown as control. (b) Representative Mtd Western blot of first-trimester tissues. Ponceau staining depicts protein loading. (c) Fold change in the transcript level of Mtd-L and Mtd-P in early first-trimester samples (6-8 weeks, black bars, $n=14)$ versus later gestations (10-12 weeks, open bars, $n=10)$ assessed by qRT-PCR. (d) Fold change in the protein level of Mtd-L, Mtd-S and Mtd-P in early first-trimester samples (6-8 weeks, black bars, $n=11)$ versus later gestations (10-12 weeks, open bars, $n=6$ ) assessed by densitometry. (e) Spatial localization of Mtd in first-trimester tissue sections. Immunopositivity is represented by brownish staining. Lower panels show TUNEL staining (greenish fluorescence) in neighboring Mtd-stained sections. Middle panels show controls (no $1^{\circ}$ antibody) (CT: cytotrophoblast; S: stroma; ST: syncytiotrophoblast). ${ }^{*} P<0.05$, Student's $t$-test

complicated by early severe onset of disease exhibited increased expression of Mtd- $L$ and particularly that of Mtd-P molecule (Figure 3e). Normal term placentae, IUGR placentae and placentae from pregnancies from essential hypertensive subjects did not show increased Mtd expression.
Interestingly, tissues from later third-trimester patients (35-37 weeks) affected by pre-eclampsia in combination with IUGR showed increased expression of Mtd-L, but not Mtd-P, when compared to control subjects. Additionally, we failed to observe differences in Mtd expression between term (late 

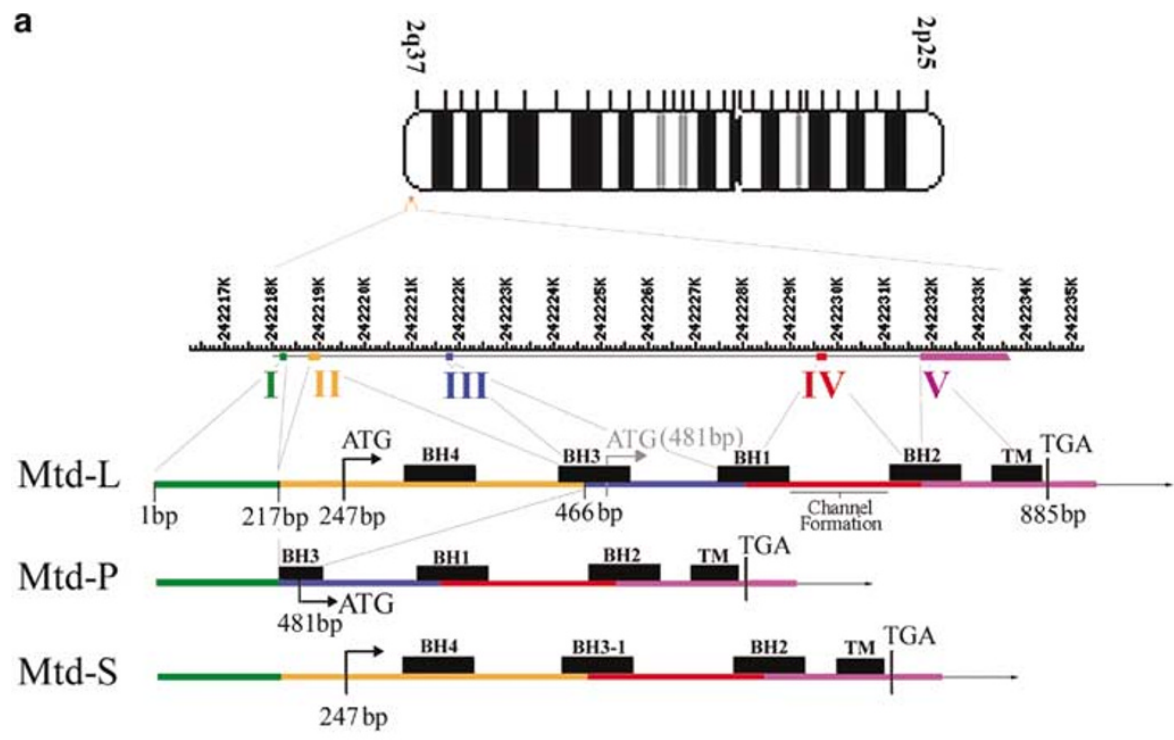

b

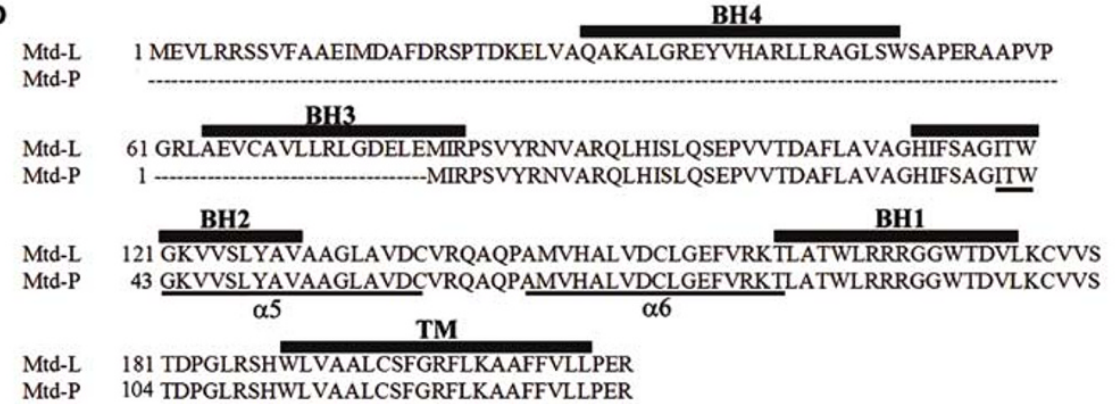

Figure 2 Genomic and mRNA maps of human Mtd isoforms. (a) Human chromosomal structure and transcript maps of Mtd isoforms. Exons (I-V) are shown in color. Conserved BH domains are shown as black boxes. (b) Protein sequence alignment between Mtd-L and Mtd-P. Exon II deletion is depicted by a dashed line

onset) pre-eclamptic tissues and appropriate controls (Figure 3f).

Immunohistochemical analysis demonstrated strong positive Mtd immunoreactivity in all trophoblast cell layers of earlyonset pre-eclamptic placental tissues when compared to controls (Figure 4). Interestingly, in pre-eclamptic tissues, increased Mtd expression was localized to syncytial knots (SK), demonstrating the potential involvement of this molecule in increased trophoblast cell death leading to increased shedding of STBMs in pre-eclampsia (lower right panel). In contrast, low/absent Mtd expression was observed in placental sections of normotensive age-matched controls (upper panels). TUNEL analysis demonstrated a notable increase in apoptotic cell death in the placental trophoblast cell layers of pre-eclamptic tissues when compared to age-matched control samples.

\section{Mtd-P is a pro-apoptotic molecule exerting its function through the mitochondrial pathway}

The apoptotic function of Mtd-P was next assessed. Mtd-P as well as Mtd-L (positive control) overexpression in Chinese hamster ovary-derived $\mathrm{CHO}$ cells and human choriocarci- noma CT-derived BeWo cells resulted in rounding-up of cells into apoptotic bodies (Figure 5a, arrows). Mtd-P overexpression in $\mathrm{CHO}$ and BeWo cells resulted in significant increased cell death within $24 \mathrm{~h}$ post-transfection when compared to cells transfected with the empty vector DNA (Figure 5a). Cell death induced by Mtd-P was similar to that induced by Mtd- $L$ in $\mathrm{CHO}$ and BeWo cells (Figure 5a).

We next investigated whether cell death was induced via a mitochondrial pathway. The JC-1 (5,5',6,6'-tetrachloro$1,1^{\prime}, 3,3^{\prime}$-tetraethylbenzimidazol-carbocyanine iodide) dye, a cationic carbocyanine fluorescent molecule with dual emission properties, was used to monitor mitochondrial membrane potential in $\mathrm{CHO}$ cells for up to $12 \mathrm{~h}$ post-transfection and preceding the morphological signs of apoptosis. Mitochondrial depolarization in Mtd-P transfection (same cell 4 and $12 \mathrm{~h}$ post-transfection) caused a leakage of J-aggregates (redorange color $(590 \mathrm{~nm})$ ) from the mitochondria into the cytoplasm leading to JC-1 monomerization (greenish color $(525 \mathrm{~nm}))$ when compared to empty vector-transfected cells (Figure 5b). JC-1-labeled FACS analyses of Mock-transfected cells exhibited a similar population scattering pattern as untreated live cells (Figure $5 \mathrm{~b}$, lower panels). Transfection alone resulted in a slight loss of red fluorescence in a live population of mock cells (quadrant 1 ) when compared to 
a

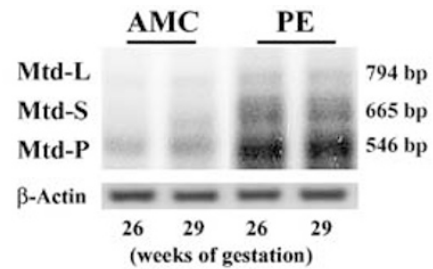

C
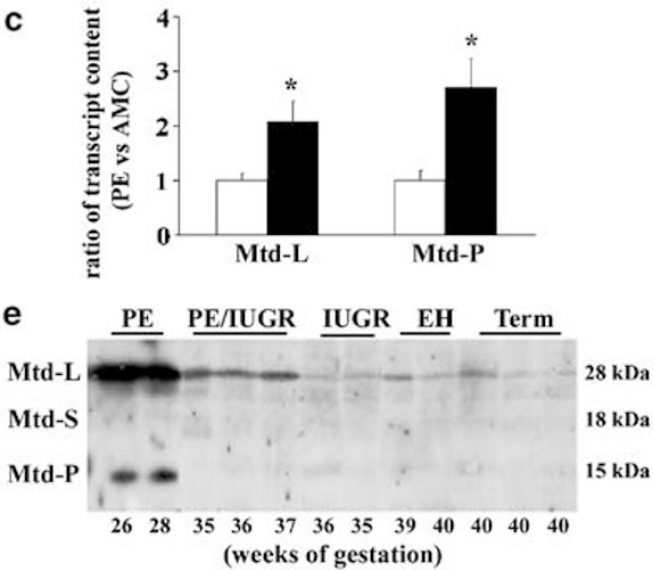

b

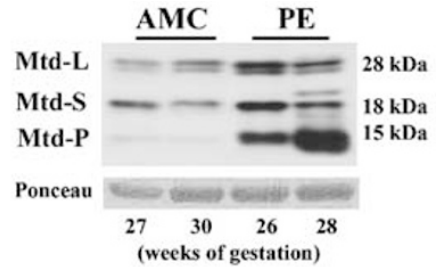

d

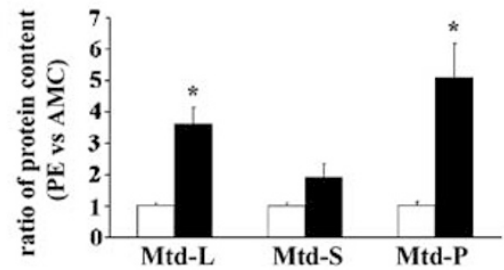

f

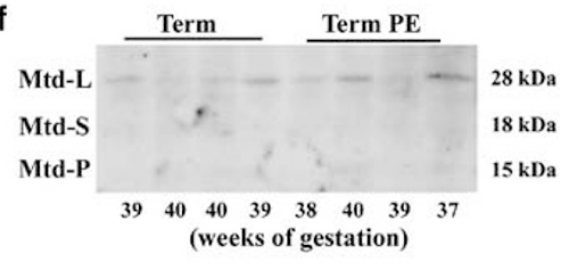

Figure 3 Mtd expression in normal and pre-eclamptic placentae. (a) Representative RT-PCR followed by Southern blotting for Mtd in tissues from age-matched control (AMC) and pre-eclamptic (PE) subjects. $\beta$-Actin is shown as control. (b) Mtd Western blot of control and pre-eclamptic samples. Ponceau staining demonstrates equal protein loading. (c) Fold change in the transcript level of Mtd-L and Mtd-P in early-onset pre-eclamptic (25-33 weeks, black bars, $n=13$ ) versus age-matched control tissues (open bars, $n=9$ ) assessed by qRT-PCR. (d) Mtd-L, Mtd-S and Mtd-P protein densitometric analysis in early-onset pre-eclampsia (black bars, $n=23$ ) versus age-matched control patients (open bars, $n=25$ ). (e) Representative Mtd immunoblot of early-onset pre-eclamptic tissues (PE), late pre-eclamptic + IUGR tissues (PE/ IUGR), and placental tissue from IUGR pregnancies (IUGR), essential hypertension (EH) and normal term patients. (f) Mtd immunoblot of late-(term) onset pre-eclamptic tissues and normal term patients. Data represent as mean \pm S.E.M. of three separate experiments. ${ }^{*} P<0.05$, Student's $t$-test

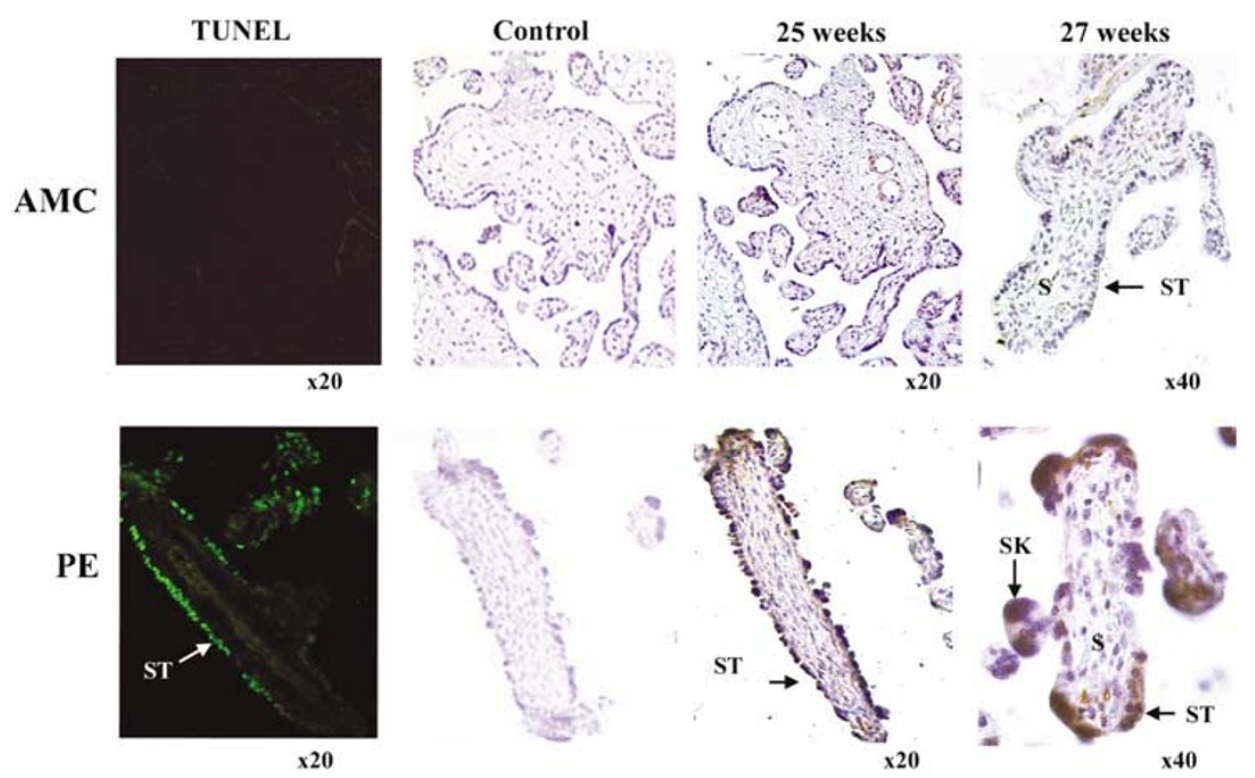

Figure 4 Mtd immunolocalization in normal and pre-eclamptic placentae. Mtd staining in normotensive 25 and 27 weeks age-matched control placentae (top) as well as 25 and 27 weeks pre-eclamptic placentae (bottom). TUNEL analysis performed in neighboring sections is also depicted. Control slides (no $1^{\circ}$ antibody) are shown (SK: syncytial knots). Immunostaining was performed in 10 different normal and pre-eclamptic placentae (25-34 weeks of gestation)

untreated live cells. Mtd-L- and Mtd-P-expressing cells exhibited a fluorescence shift in a subpopulation of cells from red (JC-1 aggregates, quadrant 1 ) to green (JC-1 monomers, quadrants 2 and 4 ). The percent of total cell population in quadrants 2 plus 4 (dead/dying cells) in mock, Mtd-L and Mtd-P transfection was respectively $4.6 \pm 0.3,24.35 \pm 0.45$ and $21.25 \% \pm 0.35$, demonstrating a significant increase ( $>5$-fold, $P<0.0001$ both isoforms) in populations of dead/ 
dying cells in Mtd-L and Mtd-P transfections when compared to mock.

Mitochondrial depolarization likely leads to the cytoplasmic release of apoptogenic factors and the activation of the caspase pathway. This was confirmed by increased cleavage of caspase-3 (17 kDa fragment in $\mathrm{CHO}$ cells and 17-19 kDa fragments in BeWo cells, the latter fragment pattern is typical of human cells), an executioner of the apoptotic pathway (Figure 5c). Moreover, Mtd-P as well as Mtd-L transfections in either $\mathrm{CHO}$ or BeWo cells resulted in nuclear DNA laddering, while mock-transfected cells did not exhibit signs of internucleosomal DNA fragmentation (Figure 5d).

\section{Mtd expression is increased under conditions of low oxygen/oxidative stress and mediates trophoblast apoptosis}

Elevated Mtd expression in early first-trimester placental tissues (5-8 weeks) (when placentation takes place in a lowoxygenated environment) as well as the increased expression in pre-eclampsia, a disease characterized by placental hypoxia, led us to hypothesize whether Mtd expression would be affected under conditions of reduced oxygenation. Therefore, we next investigated the effect of reduced oxygen in vitro on Mtd protein expression in first-trimester placental villous explants. Immunohistochemical analysis of explants incubated under 3 and $20 \%$ oxygen demonstrated increased Mtd protein expression under $3 \%$ oxygen (Figure $6 a$ and $c$ ) when compared to standard conditions $\left(20 \% \mathrm{O}_{2}\right)$ (Figure $6 \mathrm{~b}$ and d). Immunoreactivity was predominantly localized to the lowoxygen-induced extravillous trophoblast outgrowth region (EVT) as well as the CT cell layers of explants incubated under $3 \% \mathrm{O}_{2}$ (Figure $6 \mathrm{a}$ and $\mathrm{c}$ ). Low Mtd-positive immunostaining was also observed in ST cells. Stromal regions (under 3 or $20 \% \mathrm{O}_{2}$ ) were Mtd negative. Neighboring sections to those used for Mtd staining (Figure $6 \mathrm{c}$ and $\mathrm{d}$ ) were also probed with an anti-ssDNA antibody (Figure 6e-g), which identifies ssDNA characteristic of apoptotic cells. It was observed that under $3 \% \quad \mathrm{O}_{2}$ when compared to standard conditions, increased Mtd expression colocalized with active apoptosis in the same cells, demonstrating the involvement of Mtd in trophoblast cell death under conditions of reduced oxygenation. To determine which Mtd isoform (Mtd-L or Mtd-P) was induced under low oxygen tension, we next performed qRTPCR. Mtd-P gene expression, but not Mtd-L, was observed to significantly increase by 1.4 -fold $(P<0.05)$ under reduced oxygenation $(3 \%)$ when compared to standard condition (Figure 6h). Similar to the transcript expression, Western blot analysis of Mtd further confirmed increased Mtd-P protein expression under conditions of reduced oxygenation relative to standard oxygenation (Figure 6i). In contrast, Mtd-L and Mtd-S protein expressions remained unchanged between 3 and $20 \%$ oxygen (Figure 6i). Additionally, as hypoxia/ reoxygenation was recently demonstrated to be a potent inducer of trophoblast cell death, ${ }^{20}$ we tested whether Mtd expression was altered under such conditions. The transcript expressions of Mtd- $\mathrm{L}$ (three-fold, $P=0.0007$ ) and Mtd-P (1.6fold, $P<0.05$ ) were significantly increased under $\mathrm{H} / \mathrm{R}$ conditions when compared to standard conditions (Figure 6h).
Similarly, Mtd-L and Mtd-P protein expressions were also observed to increase in $\mathrm{HR}$ conditions relative to standard conditions (Figure 6i). In summary, these data collectively demonstrate a direct correlative expression between the transcript and protein levels of Mtd isoforms in various oxygenation conditions.

To assess whether Mtd has a direct involvement in trophoblast cell death, we next tested the effect of Mtd knockdown, using a previously validated antisense (AS) approach, ${ }^{21}$ in human villous explants and monitored for signs of apoptosis. We assessed the effect of AS isoformspecific oligonucleotide treatment (AS-L and AS-P) under conditions of oxidative stress $(\mathrm{HR})$, as this condition was shown to be the strongest inducer of Mtd isoforms. To confirm the success of Mtd transcript knockdown, Mtd- $L$ and Mtd-P expressions were measured using qRT-PCR in control Sand AS-treated conditions relative to untreated tissues (C). As previously observed, HR conditions significantly increased $M t d-L$ and $M t d-P$ transcript levels relative to control conditions (Figure 6j). Furthermore, AS-Mtd-L and AS-Mtd-P treatments significantly decreased their expression levels by 68 and $67 \%$, respectively, when compared to control S-treated conditions (Figure 6j). As cleaved caspase-3 expression has previously been demonstrated to be a reliable marker to trophoblast apoptosis, ${ }^{20}$ we assessed its expression by immunoblotting in explants treated with AS-Mtd ( $L$ and $P$ ) as well as control conditions (S-Mtd-L/P and no oligos: C). AS treatment resulted in markedly reduced cleavage of caspase-3 relative to control conditions, demonstrating decreased levels of apoptosis (Figure 6k).

\section{Discussion}

This study reports the placental expression of two previously characterized Mtd isoforms (Mtd-L and Mtd-S) and most importantly the identification and characterization of Mtd-P, a novel Mtd splice variant resulting from exon II skipping. Our data demonstrate that (1) Mtd-P has a distinctive developmental expression profile, (2) Mtd-P overexpression is unique to pregnancies complicated by severe early-onset pre-eclampsia, (3) Mtd-P is a proapoptotic molecule involved in trophoblast cell death and (4) Mtd-P expression is increased under conditions of reduced oxygenation and oxidative stress.

Interaction between pro- and antiapoptotic Bcl-2 family members is critical in the physiologic fine-tuning of apoptosis. ${ }^{11}$ The proapoptotic activity of the widely expressed Bax and Bak molecules is countered by their ability to interact with various antiapoptotic $\mathrm{Bcl}-2$ family members, including $\mathrm{Bcl}-2$, $\mathrm{Bcl}-\mathrm{w}$ and $\mathrm{Bcl}-\mathrm{xL} .{ }^{11}$ This contrasts the interaction capability of Mtd-L, which essentially heterodimerizes with the antiapoptotic Mcl-1 molecule. ${ }^{17,19}$ Interestingly, Mtd-S, resulting from fusion of $\mathrm{BH} 3$ and $\mathrm{BH} 1$ domains, lacks the ability to interact with any presently known antiapoptotic Bcl-2 family members. ${ }^{19}$ Mtd-P identified herein is missing 15 of the 18 amino acids that compose the $\mathrm{BH} 3$ domain. Mutation of key residues in the $\mathrm{BH} 3$ domain of $\mathrm{Mtd}-\mathrm{L}$ as well as artificial fusion of $\mathrm{BH} 3$ and $\mathrm{BH} 1$ domains in $\mathrm{Bax}$ and Bak has no effect on the killing ability of these molecules. ${ }^{19}$ As well, site-directed 
a

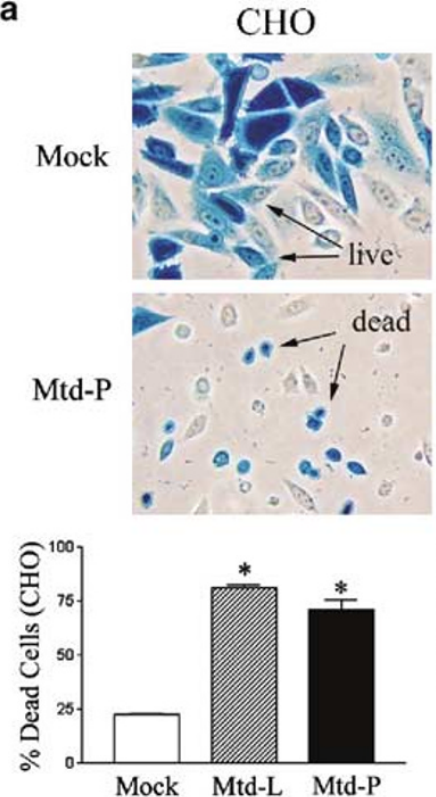

C
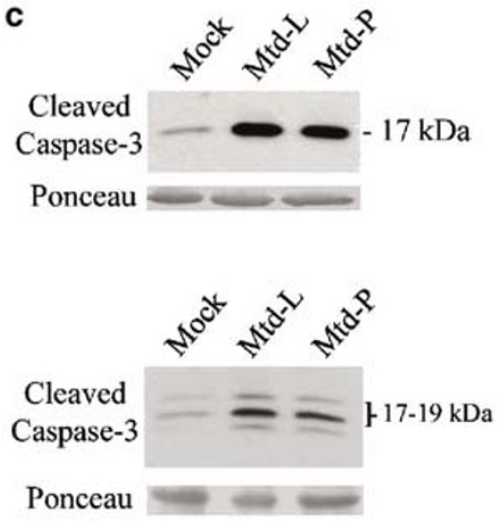

BeWo
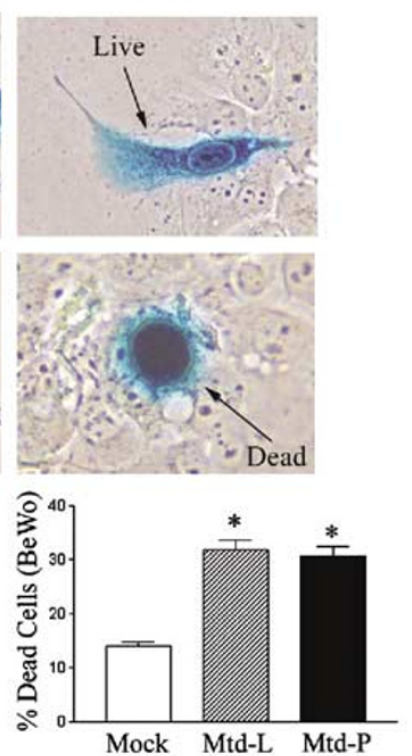

d

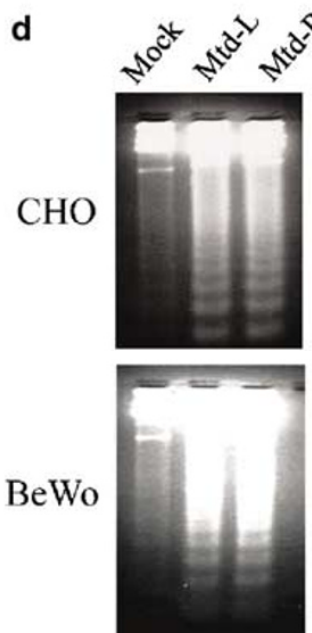

b
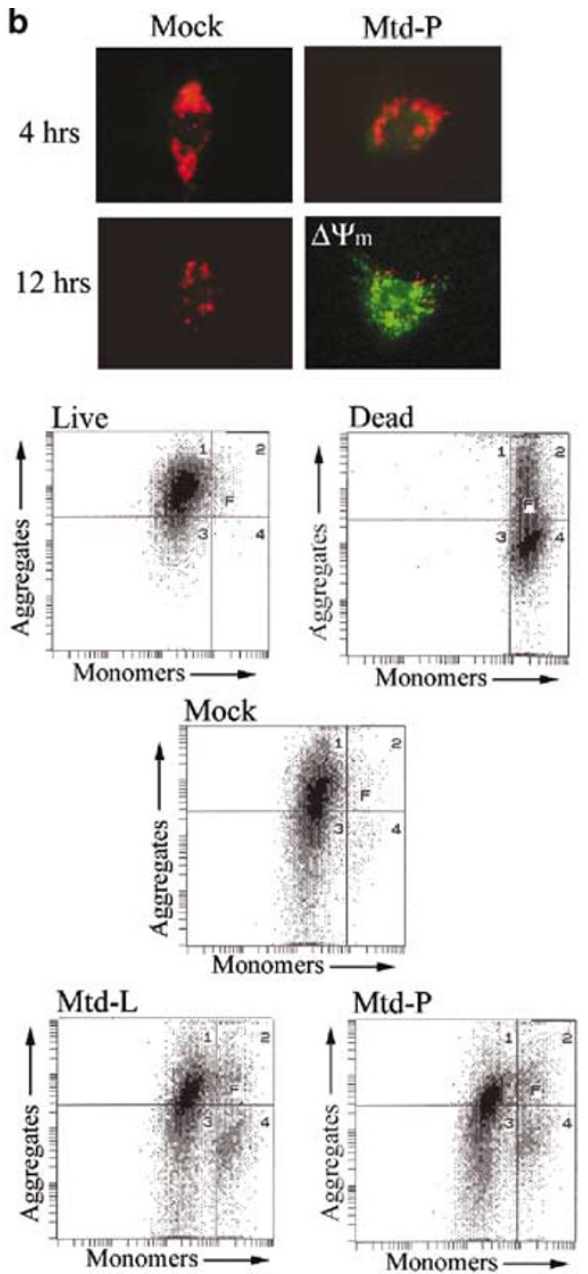

Figure 5 Functional analysis of Mtd-P in $\mathrm{CHO}$ and BeWo cells. (a) Empty vector-(top) and Mtd-P-transfected cells (bottom) (left: $\mathrm{CHO}$; right: BeWo) $24 \mathrm{~h}$ posttransfection. Blue staining ( $\beta$-gal positivity) identifies transfected cells. Graph: Percent of dead cells of total $\beta$-gal-expressing blue cells resulting from Mtd-L and Mtd-P transfections compared to empty vector-transfected control $\mathrm{CHO}$ and BeWo cells. (b) Representative mitochondrial JC-1 staining of mock-(empty vector, top) and Mtd-Ptransfected $\mathrm{CHO}$ cells (bottom). Same cell depicted 4 and $12 \mathrm{~h}$ post-transfection in each condition is shown. FACS analysis (lower panels) of JC-1-labeled populations of mock-, Mtd-L- and Mtd-P-transfected CHO cells (untreated live cells and dead cells (used as positive controls)) is represented. $Y$-axis displays FL2 measurement (red fluorescence: indicative of J-aggregates or high mitochondrial membrane potential) and the $X$-axis displays FL1 measurement (green fluorescence: indicative of J-monomers or loss of mitochondrial membrane potential). Data represent mean \pm S.E.M. of three or more separate experiments. ${ }^{*} P<0.05$, Student's $t$-test. (c) Cleaved caspase-3 Western blot analysis performed on total protein isolated from empty vector-, Mtd-L- and Mtd-P-transfected cells $18 \mathrm{~h}$ post-transfection (top: CHO; bottom: BeWo). Ponceau depicts protein loading. (d) Nuclear DNA extracted from empty vector-, Mtd-L- and Mtd-P-transfected cells $18 \mathrm{~h}$ post-transfection (top: CHO; bottom: BeWo)

mutagenesis of conserved $\mathrm{BH} 3$ residues LLRLGDEL to either glycine or alanine in Mtd-L abolishes the heteromerization properties of this protein with $\mathrm{Mcl}-1$, but does not impede its killing ability. ${ }^{19} \mathrm{BH} 3$ residues mutated in Mtd-L are not present in the open reading frame of Mtd-P, suggesting that this molecule may induce apoptosis irrespective of its interaction with Mcl-1. It should also be noted that the start methionine in Mtd-P corresponds to a glutamine residue in rat and murine protein sequences, and to a tyrosine or arginine in chicken and Drosophila sequences, respectively, ${ }^{22}$ demonstrating the species specificity of Mtd-P.
Mitochondrial depolarization in Mtd-P-transfected cells revealed important insights into its killing mechanism. The $\mathrm{BH} 3$ domain in the multidomain subfamily of proapoptotic molecules (Bok/Mtd, Bax and Bak) seems irrelevant for killing, but rather the pore-forming region consisting of the $\alpha 5$ and $\alpha 6$ helixes between the $\mathrm{BH} 2$ and $\mathrm{BH} 1$ domains and to a lesser extent the transmembrane domain appear essential for inducing cell death via mitochondrial membrane destabilization. In support of this argument, a mutant Mtd protein lacking the $\mathrm{BH} 1, \mathrm{BH} 2$ and $\mathrm{COOH}$-terminal hydrophobic tail domain was unable to induce apoptosis. ${ }^{18}$ Additionally, an artificially 
$3 \% \mathrm{O}_{2}$

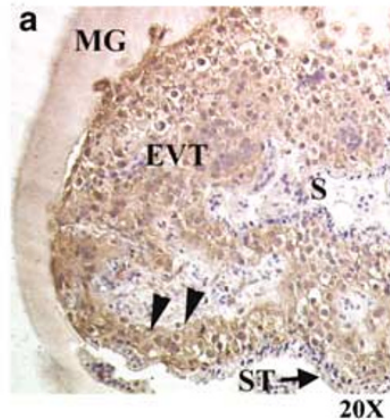

$20 \% \mathrm{O}_{2}$

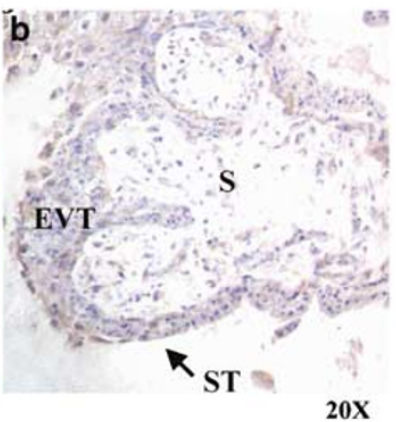

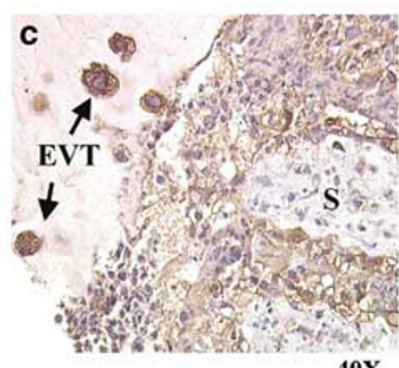

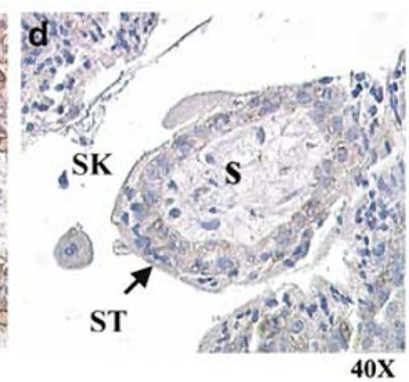

e.

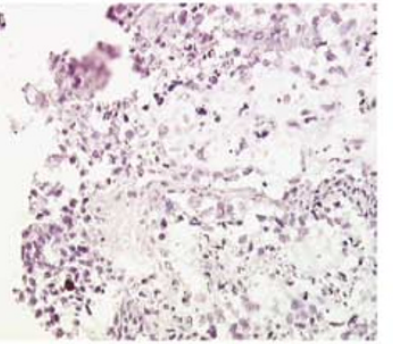

$40 \mathrm{X}$

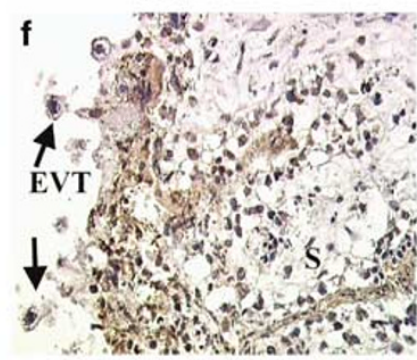

$40 \mathrm{x}$
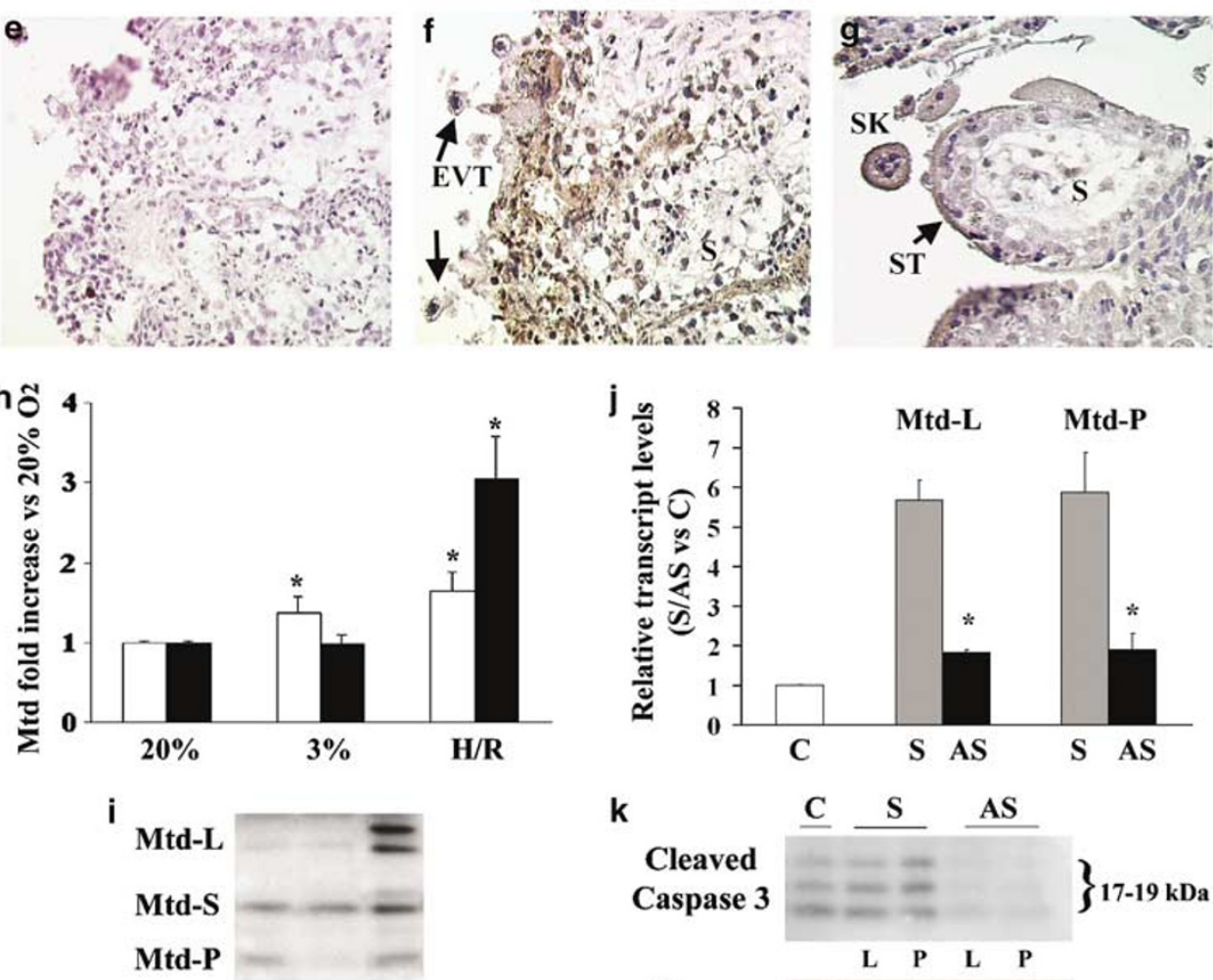

$3 \% \quad 20 \%$ HR
Mtd-L

Mtd-P

k

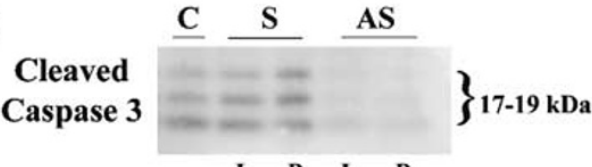

Ponceau

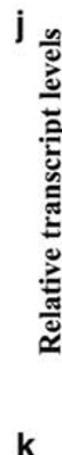

Figure 6 Effect of reduced oxygenation/oxidative stress on Mtd expression in first-trimester villous explant cultures. Immunohistochemical localization of Mtd (3\%: a, c; $20 \%:$ b, d) and ssDNA (control (no $1^{\circ} \mathrm{Ab}$ ): e; $3 \%: \mathbf{f} ; 20 \%: \mathbf{g}$ ) in explants treated under varying $\mathrm{O}_{2}$ tension is shown. Neighboring sections to Mtd (c, d) were also stained with anti-ssDNA (e, f) (higher magnification). Brownish staining represents immunopositivity (EVT: extravillous trophoblast cells). Immunostaining representative of six different experiments carried out in triplicate is shown. (h) qRT-PCR analysis of explants maintained at 3 and $20 \% \mathrm{O}_{2}$ and subjected to hypoxia/reoxygenation (H/R) showing fold changes in Mtd-L (black bars) and Mtd-P (white bars) expression levels compared to $20 \% \mathrm{O}_{2}$ (five experiments carried out in triplicate). (i) A representative Mtd immunoblot performed on protein lysates obtained from villous explants cultures under 3 and $20 \% \mathrm{O}_{2}$ as well as under conditions of HR. (j) Transcript expression levels of Mtd isoforms in explants treated with Mtd isoform-specific AS (AS-L and AS-P, gray bars) relative to control S (S-L and S-P, black bars) as assessed by qRT-PCR (data are normalized to untreated tissue: $C$, white bar). (k) A representative cleaved caspase-3 immunoblot performed on protein lysates obtained from villous explants under control conditions (C: no oligos) and treated with Mtd-S (S-L and S-P, respectively) and Mtd-AS (AS-L and AS-P, respectively) oligos. All experimental conditions were performed in triplicate in three independent experiments. Ponceau staining demonstrates protein loading. ${ }^{*} P<0.05$, Student's $t$-test 
truncated version of Mtd-L only encompassing the $\mathrm{BH} 4$ and $\mathrm{BH} 3$ domains was also incapable of inducing cell death. ${ }^{22}$ Moreover, a recently identified chicken isoform of Mtd (Mtd $\Delta \mathrm{TM}$ ) lacking the transmembrane domain was also found to adversely affect mitochondrial function and sensitize transfected lymphoma-derived cells to apoptotic stimuli, ${ }^{23}$ once again stressing the importance of the pore-forming region in inducing cell death.

Increased Mtd-P expression in pre-eclampsia may be causative for increased trophoblast cell death and shedding observed in this disease..$^{7,9,14-16,24,25}$ Our data are, to our knowledge, the first evidence of an expressional difference of a proapoptotic $\mathrm{Bcl}-2$ family member in placentae of preeclamptic versus age-matched control subjects. Previous studies have demonstrated expressional differences of other apoptotic-related molecules in pre-eclamptic and control subjects including elevated expression of serum Fas and elevated placental expression of FasL and p53 in preeclamptic placentae. ${ }^{15,26}$ Of clinical importance, Mtd-P increased expression in pre-eclamptic tissues appears unique to the early severe onset form of pre-eclampsia, as tissues obtained from normotensive age-matched and term control subjects as well as term pre-eclampsia, IUGR and essential hypertensive subjects do not exhibit elevated Mtd-P expression. This may hence be a distinctive feature of placentae from patients suffering from severe early-onset pre-eclampsia.

Our findings of increased Mtd expression in vivo at 5-8 weeks of gestation, when placental $\mathrm{pO}_{2}$ is low, and in vitro, in villous explants kept at $3 \% \mathrm{O}_{2}$, are consistent with the idea of oxygen regulating placental Mtd expression and increased apoptosis during early first-trimester placentation. Previous studies including our own have demonstrated that reduced oxygenation in vitro leads to increased levels of trophoblast proliferation. $^{27-29}$ Therefore, it is plausible that mechanisms regulating trophoblast apoptosis and proliferation may be tightly intertwined and as such may both be affected by oxygen. Interestingly, Bcl-W, a prosurvival factor, was recently demonstrated to be involved the regulation of cell cycle progression in spermatogenesis. ${ }^{30} \mathrm{Bcl}-\mathrm{xL} / \mathrm{S}$ and $\mathrm{Bcl}-2$ have also been shown to enhance the potential for cellular differentiation by delaying entry into cell cycle. ${ }^{31-34}$ Studies from others have also linked Bag-1, an antiapoptotic molecule that interacts with $\mathrm{Bcl}-2$ and a $70 \mathrm{kDa}$ heat shock protein, to a number of cellular processes besides apoptosis, including cell signaling, proliferation, transcription and cell motility. ${ }^{30,35}$ Altogether, these findings are indicative that members of the $\mathrm{Bcl}-2$ family may play a central role in the regulation of global cellular processes other than apoptosis, possibly via as yet undiscovered pathways involved in cell fate decisions. The exact role of Mtd-P in regulating CT cell differentiation under conditions of reduced oxygenation remains to be elucidated.

What is particularly important in our findings is the increased expression of Mtd under conditions of low oxygen and hypoxia-reoxygenation. Previous studies have demonstrated that under hypoxia, primary CT cells, particularly populations isolated from pre-eclamptic placentae, exhibit increased levels of apoptosis. ${ }^{25,36}$ Importantly, reduced uter-oplacental oxygenation and hypoxia-reoxygenation, a direct cause of oxidative stress as it may be the case in early severe onset pre-eclampsia, are potent inducers of villous tropho- blast cell death. ${ }^{20}$ Our data herein corroborate these findings. Using AS knockdown, we demonstrated that Mtd is a direct regulator of trophoblast cell death under conditions of oxidative stress. Moreover, we have shown that increased expression of Mtd-P as well as Mtd-L in trophoblast cells results in increased apoptotic cell death as measured by caspase-3 cleavage and internucleosomal DNA fragmentation.

Since several putative hypoxia-responsive elements are present in the human Mtd promoter region, it is hence plausible that Mtd expression is under HIF-1 (a transcriptional regulator of oxygen-responsive genes) control. Studies including our own have demonstrated that HIF- $1 \alpha$, the oxygen labile moiety of HIF-1, is elevated in pre-eclamptic placentae. ${ }^{37,38}$ Recent studies have demonstrated that expression of other proapoptotic Bcl-2 family members (Nix and Nip3) is directly regulated by HIF- $1 \alpha$ under conditions of reduced oxygenation. ${ }^{39,40}$ Interestingly, hypoxia has also been shown to increase the expression of the proapoptotic Bax and decrease the expression of the antiapoptotic $\mathrm{Bcl}-2$ molecule in human trophoblast cells. ${ }^{36}$ Similar to what we demonstrated here, these studies are supporting evidence that oxygen plays a key role in regulating the expression of molecules within the $\mathrm{Bcl}-2$ family and highlight the importance of the mitochondrial pathway in regulating low-oxygen-induced apoptosis. Whether increased Mtd expression in low $\mathrm{pO}_{2}$ /oxidative stress is directly regulated by $\mathrm{HIF}-1 \alpha$ or potentially other hypoxia-induced transcription factors such as NF- $\kappa$ B and AP-1 remains to be established. Finally, we should point out that increased Mtd expression in pre-eclampsia may also be p53-dependent, as this transcription factor (a known regulator of $\mathrm{Mtd}$ ) is increased in hypoxic/oxidative stress conditions as well as in pre-eclampsia and IUGR. ${ }^{15,16,36,41,42}$

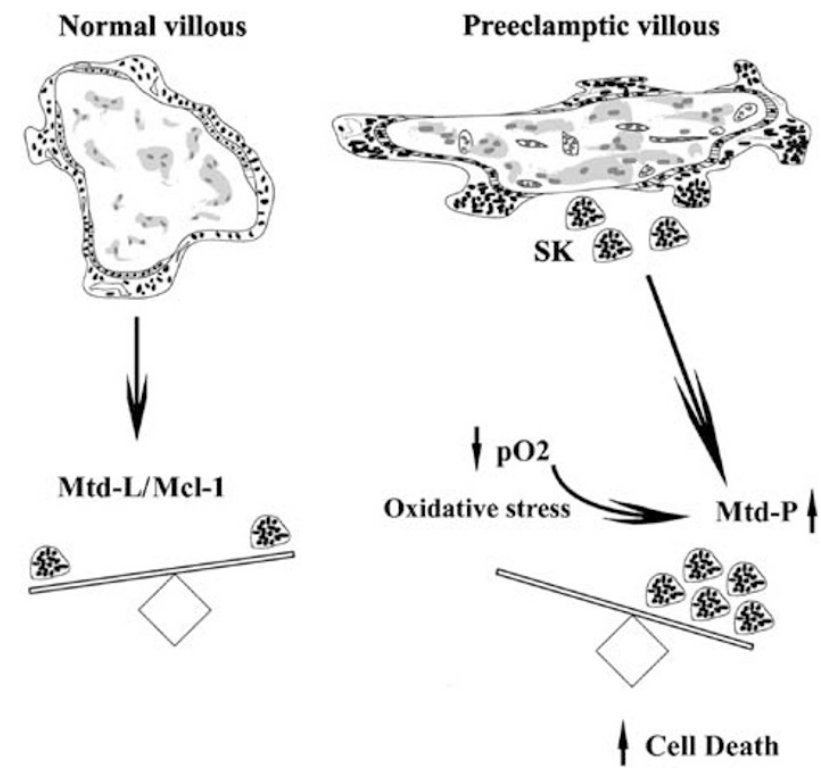

Figure 7 Putative model: Mtd role in normal and pre-eclamptic placentae. In pre-eclampsia, alteration in placental oxygenation, due to low $\mathrm{pO}_{2}$ or oxidative stress (HR), may be responsible for the aberrant expression of Mtd-P, which in turn leads to a change in the physiological apoptotic rheostat in trophoblast cells. This imbalance results in accelerated syncytiotrophoblast cell death resulting in increased shedding of trophoblast microfragments in the maternal circulation 
Based on our putative model (Figure 7), we postulate that Mtd overexpression in pre-eclampsia, following reduced oxygenation and/or oxidative stress, shifts the intrinsic trophoblast apoptotic rheostat toward a death pathway and results in increased release of trophoblast microfragments in the maternal circulation. We conclude that Mtd-P is a novel molecule that may be responsible for the molecular events leading to the clinical manifestations of this devastating disorder of pregnancy.

\section{Materials and Methods}

\section{Tissue collection}

Collection was in accordance with the participating institutions' ethics guidelines. First-trimester human placental tissues (5-13 weeks of gestation, $n=30$ ) were obtained from elective terminations of pregnancies by dilatation and curettage. Pre-eclamptic group was selected based on ACOG clinical and pathological criteria. ${ }^{43}$ Calcified, necrotic and visually ischemic areas were omitted from sampling. Patients with diabetes, infections and kidney disease were excluded. Pregnant patients with essential hypertension ( $\mathrm{EH} ; n=4$, at term) and pregnancies affected by IUGR ( $n=6$, gestational age 32-36 weeks with fetal weight less than 5th percentile) without pre-eclampsia were included as controls. Preterm control patients did not show signs of pre-eclampsia or other placental disease. Preterm deliveries were due to multiple pregnancy $(27 \%)$, preterm labor due to incompetent cervix (41\%), premature preterm rupture of membrane (18\%) and spontaneous rupture of membranes (14\%). Clinical data are summarized in Table 1.

\section{Human chorionic villous explant culture}

Explant cultures were performed as previously described. ${ }^{27}$ Explants were maintained in standard condition $\left(5 \% \mathrm{CO}_{2}\right.$ in $95 \%$ air) or in an atmosphere of $3 \% \mathrm{O}_{2} / 92 \% \mathrm{~N}_{2} / 5 \% \mathrm{CO}_{2}$ for $48 \mathrm{~h}$ at $37^{\circ} \mathrm{C}$. In separate experiments, hypoxia/reoxygenation was performed as previously described ${ }^{20}$ from $20 \% \mathrm{O}_{2}$ to low-oxygen conditions: $2-3 \% \mathrm{O}_{2}$ to reoxygenation $20 \% \mathrm{O}_{2}$.

\section{RNA analysis and targeting (antisense knockdown)}

RNA was extracted using a Rneasy Mini Kit (Qiagen), random hexamer reverse transcribed and amplified by 20 cycles of PCR $\left(5 \mathrm{~min}\right.$ at $95^{\circ} \mathrm{C}$, cycle: $30 \mathrm{~s}$ at $95^{\circ} \mathrm{C}, 30 \mathrm{~s}$ at $55^{\circ} \mathrm{C}$ and $1.5 \mathrm{~min}$ at $72^{\circ} \mathrm{C}$ ). The primers used were as follows: Mtd (NM_032515): forward 5'-ATCCTGAAGCCA GAACTCCA-3', reverse 5'-AAGATGTGTTCGGGTGCTGA-3' (predicted sizes: Mtd-L: $794 \mathrm{bp}$; Mtd-S: $665 \mathrm{bp}$ ); $\beta$-actin (NM_001101): forward 5' CTTCTACAATGAGCTGCGTG-3', reverse 5'-TCATGAGGTAGTCAGTC AGG-3' (predicted size $=304 \mathrm{bp}$ ). Products were confirmed by sequencing. No signal was detected without addition of reverse transcriptase. RT-PCR products were analyzed by Southern blotting using Mtd and $\beta$-actin cDNAs labeled with $\left[\alpha-{ }^{32} \mathrm{P}\right] \mathrm{dCTP}$ (PerkinElmer Life Sciences), using a random hexamer approach. Quantitative PCR was performed using the SYBR Green I dye DyNamo ${ }^{\mathrm{TM}}$ HS kit (MJ Research) based on the manufacturer's protocol using isoform-specific primers (Mtd-L: forward 5'-GCCTGGCTGAGGTGTGC-3', Mtd-P: forward 5'-GCGGGAGAGGC GATGA, reverse (both $L$ and P) $5^{\prime}$-TGCAGAGAAGATGTGGCCA- $3^{\prime}$ ). Analysis was carried out using the DNA Engine Opticon ${ }^{\mathbb{R}} 2$ System (MJ Research). Data were normalized against expression of $18 \mathrm{~S}$ ribosomal RNA as previously described. ${ }^{44}$ Mtd knockdown was performed in villous explants using phosphorothioated (all positions) $S$ and AS oligos designed against Mtd transcript NM_032515 at a final concentration of $10 \mu \mathrm{M}$ (S-L: 5'-CATGGAGGTGCTGCGG-3', AS-L: 5'-CCGCAGCACCTCCATG-3', S-P: 5'-AGGCGATGAGCTGGAGATGA-3', AS-P: 5'-TCATCTCCAGCT CATCGCCT-3').

\section{Western blot analysis}

Western blot analyses were performed as previously described. ${ }^{45}$ Primary antibody $(1: 1000)$ used was rabbit polyclonal Mtd antibody (generous gift of Dr. J Tilly), ${ }^{46}$ or cleaved caspase-3 rabbit polyclonal antibody (Cell Signaling). For Mtd antibody, preimmune serum was used as control. Secondary antibody $(1: 5000)$ was horseradish peroxidase-conjugated anti-rabbit (Santa Cruz Biotechnology). All immunoblots were checked for equivalent protein loading using ponceau staining.

\section{Immunohistochemistry}

Immunohistochemical analyses were performed as previously described. ${ }^{27,45}$ Primary antibody was rabbit polyclonal anti-Mtd $(1: 200)$ or mouse monoclonal anti-ssDNA $(1: 500)$, the latter used based on the manufacturer's protocol (MAB3299, Chemicon). Secondary antibody $(1: 400)$ was biotinylated goat anti-rabbit or goat anti-mouse IgG (Vector Laboratories).

Table 1 Clinical parameters of pre-eclamptic and control participants

\begin{tabular}{|c|c|c|}
\hline & Pre-eclamptic subjects $(n=66)$ & Control subjects $(n=59)$ \\
\hline Mean maternal age (years) & $29.9 \pm 6.2$ & $31.8 \pm 5.6$ \\
\hline Mean gestational age (range in weeks) & $\begin{array}{l}\text { Preterm: } 30.8 \pm 3.1(25-34, n=51) \\
\text { Term: } 38.9 \pm 1.1(37-41, n=15)\end{array}$ & $\begin{array}{l}\text { Preterm: } 30.4 \pm 3.4(23-36, n=36) \\
\text { Term: } 39.2 \pm 1.0(37-41, n=23)\end{array}$ \\
\hline Blood pressure & $\begin{array}{l}\text { Systolic: } 17 \overline{7} \pm 7.2 \\
\text { Diastolic: } 114 \pm 4.5\end{array}$ & $\begin{array}{l}\text { Systolic: } 11 \overline{2} \pm 6.6 \\
\text { Diastolic: } 68 \pm 6.0\end{array}$ \\
\hline Proteinuria & $3.0 \pm 1$ & Absent \\
\hline Edema & $\begin{array}{l}\text { Present: } 81 \% \\
\text { Absent: } 19 \%\end{array}$ & Absent \\
\hline Fetal weight $(\mathrm{g})$ & $\begin{array}{l}\text { Preterm AGA: } 1476 \pm 456(n=40) \\
\text { Preterm IUGR: } 1065 \pm 506(n=11) \\
\text { Term AGA: } 3295 \pm 478(n=15)\end{array}$ & $\begin{array}{l}\text { Preterm AGA: } 1497 \pm 628 \\
\text { Term AGA: } 3359 \pm 409\end{array}$ \\
\hline Mode of delivery & $\begin{array}{l}\text { CS: } 90 \% \\
\text { VD: } 10 \%\end{array}$ & $\begin{array}{l}\text { CS: } 45 \% \\
\text { VD: } 55 \%\end{array}$ \\
\hline
\end{tabular}

Data are represented as mean \pm S.D. Maternal age of participants ranged from 16 to 44 years. AGA: appropriate for gestational age; IUGR: intrauterine growth restriction ( $<5$ th percentile); VD: vaginal delivery; CS: cesarian section delivery 


\section{TUNEL}

The in situ Cell Death Detection kit (Roche Molecular Biochemicals) was used based on the manufacturer's protocol.

\section{Plasmid construction}

Open reading frames (ORF) of Mtd- $L$ and Mtd- $P$ were directional cloned in pcDNA3.1/Hygro $(+)$ (Invitrogen). Forward and reverse primers used encoded a Kpnl and a BamHI restriction site, respectively. The Primers were as follows: Mtd-P: forward 5'-CCCGGTACCACCATGATCCGGC CCAGCGTCTAC-3' ${ }^{\prime}$, reverse $5^{\prime}$-CCCGGATCCGGGTCATCTCTCTGGCA GCAGCAC-3'; Mtd-L: forward 5'-CCCGGTACCACCATGATCCGGCCCA GCGTCTAC-3', reverse 5'-CCCGGATCCGGGTCATCTCTCTGGCAACA ACAGGAA-3'

\section{Transfection studies}

Cell culture ( $\mathrm{CHO}$ and BeWo; ATCC), transfection, fixation and $\beta$-gal staining were performed as previously described. ${ }^{17}$ BeWo cells were cultured based on the manufacturer's protocol (ATCC). Transfection was performed with $1.5 \mu \mathrm{g}$ of construct per 35-mm plate (empty pcDNA3.1/

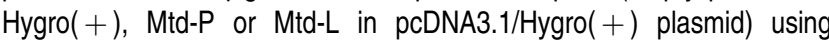
lipofectamine reagent (Invitrogen) in combination with $0.1 \mu \mathrm{g}$ fraction of pcDNA3.1/Hygro $(+)$ encoding the lacZ gene based on the manufacturer's recommendations.

\section{DNA laddering}

Genomic DNA was extracted $24 \mathrm{~h}$ post-transfection as previously described. ${ }^{47}$ Samples were separated on $2 \%$ (wt/vol) agarose gel containing $0.5 \mu \mathrm{g} / \mathrm{ml}$ ethidium bromide for $2 \mathrm{~h}$ at $40 \mathrm{~V}$ and visualized using a UV transluminator.

\section{Mitochondrial membrane potential analysis}

Membrane potential was assessed by JC- 1 ( $3 \mu \mathrm{g} / \mathrm{ml}$ working concentration; Molecular Probes) staining based on the manufacturer's protocol for staining in culture dish and FACS analysis. Images were captured using an inverted fluorescent microscope (Leica DMIRB) equipped with fluorescein and rhodamine filters. Stained $\mathrm{CHO}$ cells (live cells, dead cells (floating fraction of serum-starved cells) and transfected conditions) were subjected to FACS analysis on an EPICS Elite (Beckman-Coulter) using green (JC-1 monomers) and red (JC-1 aggregates) fluorescence signals resolved by detection in conventional FL1 and FL2 channels, respectively.

\section{Statistical analysis}

Data are represented as mean+S.E.M. of at least three separate experiments carried out in triplicate. Statistical difference was determined by Student's $t$-test for paired groups, significance defined as $P<0.05$.

\section{Acknowledgements}

We thank Dr. Ljiljiana Petkovic for placental collection. Our appreciation goes out to Drs. Knox Ritchie and Alan Bocking for their constant support. We thank Ms. Cheryl Smith for her assistance in FACS analyses, Ms. Mari Chijiiwa for the artwork and Dr. Elen Kostopoulos for her assistance in collection of clinical data. This work was supported by the Canadian Institutes of Health Research (CIHR) Grants (MT-1406 and MOP-62845) to Isabella Caniggia. Nima Soleymanlou is supported by the Restracomp Training Program at the Hospital for Sick Children and the Ontario Graduate Scholarship Program at the University of Toronto. Isabella Caniggia and Andrea Jurisicova are recipients of CIHR Scholarship Awards. Martin Post is the holder of a Canadian Research Chair (tier 1) in Fetal, Neonatal and Maternal Health.

\section{References}

1. Cunningham FG and Lindheimer MD (1992) Hypertension in pregnancy. N. Engl. J. Med. 326: 927-932

2. Meekins JW, Pijnenborg R, Hanssens M, McFadyen IR and van Asshe A (1994) A study of placental bed spiral arteries and trophoblast invasion in normal and severe pre-eclamptic pregnancies. Br. J. Obstet. Gynaecol. 101: 669-674

3. Aquilina J and Harrington K (1996) Pregnancy hypertension and uterine artery Doppler ultrasound. Curr. Opin. Obstet. Gynecol. 8: 435-440

4. Redman CW and Sargent IL (2000) Placental debris, oxidative stress and preeclampsia. Placenta 21: 597-602

5. Roberts JM and Hubel CA (1999) Is oxidative stress the link in the two-stage model of pre-eclampsia? Lancet 354: 788-789

6. Brosens I and Renaer M (1972) On the pathogenesis of placental infarcts in pre-eclampsia. J. Obstet. Gynaecol. Br. Commonw. 79: 794-799

7. Sargent IL, Germain SJ, Sacks GP, Kumar S and Redman CW (2003) Trophoblast deportation and the maternal inflammatory response in preeclampsia. J. Reprod. Immunol. 59: 153-160

8. Huppertz B, Frank HG, Kingdom JC, Reister F and Kaufmann P (1998) Villous cytotrophoblast regulation of the syncytial apoptotic cascade in the human placenta. Histochem. Cell Biol. 110: 495-508

9. DiFederico E, Genbacev $O$ and Fisher SJ (1999) Preeclampsia is associated with widespread apoptosis of placental cytotrophoblasts within the uterine wall. Am. J. Pathol. 155: 293-301

10. Huppertz B, Frank HG, Reister F, Kingdom J, Korr H and Kaufmann P (1999) Apoptosis cascade progresses during turnover of human trophoblast: analysis of villous cytotrophoblast and syncytial fragments in vitro. Lab. Invest. 79: 1687-1702

11. Gross A, McDonnell JM and Korsmeyer SJ (1999) BCL-2 family members and the mitochondria in apoptosis. Genes Dev. 13: 1899-1911

12. Hsu SY and Hsueh AJ (2000) Tissue-specific Bcl-2 protein partners in apoptosis: an ovarian paradigm. Physiol. Rev. 80: 593-614

13. Ratts VS, Tao XJ, Webster CB, Swanson PE, Smith SD, Brownbill P, Krajewski S, Reed JC, Tilly JL and Nelson DM (2000) Expression of BCL-2, BAX and BAK in the trophoblast layer of the term human placenta: a unique model of apoptosis within a syncytium. Placenta 21: 361-366

14. Allaire AD, Ballenger KA, Wells SR, McMahon MJ and Lessey BA (2000) Placental apoptosis in preeclampsia. Obstet. Gynecol. 96: 271-276

15. Levy R, Smith SD, Yusuf K, Huettner PC, Kraus FT, Sadovsky Y and Nelson DM (2002) Trophoblast apoptosis from pregnancies complicated by fetal growth restriction is associated with enhanced p53 expression. Am. J. Obstet. Gynecol. 186: 1056-1061

16. Ishihara N, Matsuo $H$, Murakoshi $H$, Laoag-Fernandez JB, Samoto $T$ and Maruo T (2002) Increased apoptosis in the syncytiotrophoblast in human term placentas complicated by either preeclampsia or intrauterine growth retardation. Am. J. Obstet. Gynecol. 186: 158-166

17. Hsu SY, Kaipia A, McGee E, Lomeli M and Hsueh AJ (1997) Bok is a proapoptotic $\mathrm{Bcl}-2$ protein with restricted expression in reproductive tissues and heterodimerizes with selective anti-apoptotic Bcl-2 family members. Proc. Natl. Acad. Sci. USA 94: 12401-12406

18. Inohara N, Ekhterae D, Garcia I, Carrio R, Merino J, Merry A, Chen S and Nunez G (1998) Mtd, a novel Bcl-2 family member activates apoptosis i $\mathrm{n}$ the absence of heterodimerization with Bcl-2 and Bcl-XL. J. Biol. Chem. 273: 8705-8710

19. Hsu SY and Hsueh AJ (1998) A splicing variant of the Bcl-2 member Bok with a truncated $\mathrm{BH} 3$ domain induces apoptosis but does not 
dimerize with antiapoptotic Bcl-2 proteins in vitro. J. Biol. Chem. 273: 30139-30146

20. Hung TH, Skepper JN, Charnock-Jones DS and Burton GJ (2002) Hypoxia-reoxygenation: a potent inducer of apoptotic changes in the human placenta and possible etiological factor in preeclampsia. Circ. Res. 90: 1274-1281

21. Caniggia I, Taylor CV, Ritchie JW, Lye SJ and Letarte M (1997) Endoglin regulates trophoblast differentiation along the invasive pathway in human placental villous explants. Endocrinology 138: 4977-4988

22. Zhang H, Holzgreve W and De Geyter $\mathrm{C}$ (2000) Evolutionarily conserved Bok proteins in the Bcl-2 family. FEBS Lett. 480: 311-313

23. Brown CY, Bowers SJ, Loring G, Heberden C, Lee RM and Neiman PE (2004) Role of Mtd/Bok in normal and neoplastic B-cell development in the bursa of Fabricius. Dev. Comp. Immunol. 28: 619-634

24. Leung DN, Smith SC, To KF, Sahota DS and Baker PN (2001) Increased placental apoptosis in pregnancies complicated by preeclampsia. Am. J. Obstet. Gynecol. 184: 1249-1250

25. Crocker IP, Cooper S, Ong SC and Baker PN (2003) Differences in apoptotic susceptibility of cytotrophoblasts and syncytiotrophoblasts in normal pregnancy to those complicated with preeclampsia and intrauterine growth restriction. Am. J. Pathol. 162: 637-643

26. Hsu CD, Harirah H, Basherra H and Mor G (2001) Serum soluble Fas levels in preeclampsia. Obstet. Gynecol. 97: 530-532

27. Caniggia I, Mostachfi H, Winter J, Gassmann M, Lye SJ, Kuliszewski M and Post M (2001) Hypoxia-inducible factor-1 mediates the biological effects of oxygen on human trophoblast differentiation through TGFbeta(3). J. Clin. Invest. 105: 577-587

28. Genbacev O, Zhou Y, Ludlow JW and Fisher SJ (1997) Regulation of human placental development by oxygen tension. Science 277: 1669-1672

29. Genbacev O, Joslin R, Damsky CH, Polliotti BM and Fisher SJ (1996) Hypoxia alters early gestation human cytotrophoblast differentiation/invasion in vitro and models the placental defects that occur in preeclampsia. J. Clin. Invest. 97: 540-550

30. Clevenger CV, Thickman K, Ngo W, Chang WP, Takayama S and Reed JC (1997) Role of Bag-1 in the survival and proliferation of the cytokine-dependent lymphocyte lines, $\mathrm{Ba} / \mathrm{F} 3$ and $\mathrm{Nb2}$. Mol. Endocrinol. 11: 608-618

31. Linette GP, Li Y, Roth K and Korsmeyer SJ (1996) Cross talk between cell death and cell cycle progression: BCL-2 regulates NFAT-mediated activation. Proc. Natl. Acad. Sci. USA 93: 9545-9552

32. Vairo G, Innes KM and Adams JM (1996) Bcl-2 has a cell cycle inhibitory function separable from its enhancement of cell survival. Oncogene 13: 1511-1519

33. Chattopadhyay A, Chiang CW and Yang E (2001) BAD/BCL-[X(L)] heterodimerization leads to bypass of G0/G1 arrest. Oncogene 20: 4507-4518
34. Fridman JS, Rehemtulla A, Hofmann A, Blau HM and Maybaum J (1998) Expression of $\mathrm{Bcl}-\mathrm{XS}$ alters cytokinetics and decreases clonogenic survival in $\mathrm{K} 12$ rat colon carcinoma cells. Oncogene 17: 2981-2991

35. Townsend PA, Cutress RI, Sharp A, Brimmell M and Packham G (2003) BAG1: a multifunctional regulator of cell growth and survival. Biochim. Biophys. Acta 1603: 83-98

36. Levy R, Smith SD, Chandler K, Sadovsky Y and Nelson DM (2000) Apoptosis in human cultured trophoblasts is enhanced by hypoxia and diminished by epidermal growth factor. Am. J. Physiol. Cell Physiol. 278: C982-C988

37. Caniggia I and Winter JL (2002) Adriana and Luisa Castellucci Award lecture 2001. Hypoxia inducible factor-1: oxygen regulation of trophoblast differentiation in normal and pre-eclamptic pregnancies - a review. Placenta 23 (Suppl. A): S47-S57

38. Rajakumar A, Whitelock KA, Weissfeld LA, Daftary AR, Markovic N and Conrad KP (2001) Selective overexpression of the hypoxia-inducible transcription factor, HIF-2alpha, in placentas from women with preeclampsia. Biol. Reprod. 64: 499-506

39. Sowter HM, Ratcliffe PJ, Watson P, Greenberg AH and Harris AL (2001) HIF-1dependent regulation of hypoxic induction of the cell death factors BNIP3 and NIX in human tumors. Cancer Res. 61: 6669-6673

40. Bruick RK (2000) Expression of the gene encoding the proapoptotic Nip3 protein is induced by hypoxia. Proc. Natl. Acad. Sci. USA 97: 9082-9087

41. Yakovlev AG, Di Giovanni S, Wang G, Liu W, Stoica B and Faden Al (2004) BOK and NOXA are essential mediators of p53-dependent apoptosis. J. Biol. Chem. 279: 28367-28374

42. Graeber TG, Peterson JF, Tsai M, Monica K, Fornace AJ and Giaccia AJ (1994) Hypoxia induces accumulation of p53 protein, but activation of a G1-phase checkpoint by low-oxygen conditions is independent of p53 status. Mol. Cell. Biol. 14: 6264-6277

43. ACOG practice bulletin (2002) Diagnosis and management of preeclampsia and eclampsia. Number 33, January 2002. American College of Obstetricians and Gynecologists. Int. J. Gynaecol. Obstet. 77: 67-75

44. Livak KJ and Schmittgen TD (2001) Analysis of relative gene expression data using real-time quantitative PCR and the 2(-Delta Delta $\mathrm{C}(\mathrm{T})$ ) method. Methods 25: 402-408

45. MacPhee DJ, Mostachfi H, Han R, Lye SJ, Post M and Caniggia I (2001) Focal adhesion kinase is a key mediator of human trophoblast development. Lab. Invest. 81: 1469-1483

46. Jurisicova A, Johnson AL, Casper RF and Tilly JL (2000) Developmentally regulated expression of the pro-apoptotic Bcl-2 family member, Mtd/Bok, in oocytes and preimplantation embryos. Endocr. Soc. 131: 316

47. Herrmann M, Lorenz HM, Voll R, Grunke M, Woith W and Kalden JR (1994) A rapid and simple method for the isolation of apoptotic DNA fragments. Nucleic Acids Res. 22: 5506-5507 